\title{
EDITORIAL
}

\section{Recent Advances in Plant Extract Stabilization Using Supercritical Fluids}

The Open Chemical Engineering Journal is publishing a special issue, that is, a Hot Topic entitled "Recent advances in plant extract stabilization using supercritical fluids". Six papers are included in this HT focusing in various aspects of applications of supercritical fluids to extract and stabilize plant extracts: two papers present new experimental data on co-precipitation of betacarotene and polymer, one gives new data on modelling the system neem seeds/ carbon dioxide using fuzzy logic, an innovation to the field. The other three articles are review articles dealing with different aspects of plant extract stabilization using supercritical carbon dioxide applied to essential oils, to carotenoids, and to phenolic compounds.

The special issue provided an opportunity for publication of original peer-reviewed full-length research and review articles on new research findings and developments in stabilization of plant extracts using supercritical fluids. Bioactive compounds are used in the cosmetic, food, and pharmaceutical industries. New techniques to obtain these compounds from a variety of sources are continuously developed. An example of such technique is supercritical fluid extraction (SFE); this technique has proved to be technically viable for several types of solid substratum. Nonetheless, new experimental data and modelling work are still needed in order to transfer this technology to industry. Additional equilibrium data are also needed in order to optimize the separation step in SFE. The article by Giufrida et al. [1] presents new equilibrium data for ternary systems of $\mathrm{CO}_{2}+$ ethanol + curcumin and $\mathrm{CO}_{2}+$ ethyl acetate + curcumin. Curcuminoids are being acknowledged lately as an important supplement for preventing and even cure certain types of cancer. Franceschi et al. [2] provide new data for the co-precipitation of beta-carotene and poly(hydroxybutirate-co-hydroxyvalerate) (PHBV) with dichloromethane as organic solvent; the results are promising in applying this technique to other systems. Zahedi et al. [3] studied the extraction from neem seeds using supercritical carbon dioxide with methanol as co-solvent. The authors neuro-fuzzy network to the model the system; gray box model was validated with experimental data. The article by Martín et al. [4] is a review dedicated to the applications of encapsulation and coprecipitation of essential oils with supercritical fluids. Essential or volatile oils are a major class of substances responsible for the aroma and taste of several foods; they are used in cosmetic and pharmaceutical industries due to their innumerable bioactivities such as, antioxidant, bactericide, among several others. Santos and Meireles [5] dedicated their review to the encapsulation of carotenoids. Some carotenoids are pro vitamin A, such as beta-carotene while others are not, such as lycopene. These substances are used in food, cosmetics, and medicinal to impart color as well as a natural antioxidant. Maróstica Junior et al. [6] reviewed the applications of supercritical fluids in obtaining and stabilizing phenolic compounds; these are compounds associated with a variety of bioactivity including anti-aging, therefore, are extensively used in cosmetics, foods, and medicines. Bioactive compounds are also produced by other techniques such as microwave assisted extraction, ultrasound assisted extraction, solvent extraction using green solvents, steam distillation; these processes are also classified as green or clean technologies. Nonetheless, one of the big issues after obtaining the extract is the stabilization of such extract. Techniques that use supercritical solvents to form micro and nano particles can be used to stabilize these extracts. This special issue served to stimulate the studies on these areas that are extremely important for academia and industry. 


\section{REFERENCES}

[1] W. M. Giufrida, R. Favareto, V. F. Cabral, M. A. A. Meireles, L. Cardozo-Filho, M. L. Corazza, "High-pressure vapor-liquid equilibrium data for ternary systems $\mathrm{CO}_{2}+$ organic solvent + curcumin", Open Chem. Eng. J., vol. 4, pp. 3-10, 2010.

[2] E. Franceschi, A. Cezaro, S. R. S. Ferreira, M. H. Kunita ${ }^{4}$, E. C. Muniz ${ }^{4}$, A. F. Rubira, J. V. Oliveira, " Co-precipitation of beta-carotene and biopolymer using supercritical carbon dioxide as antisolvent", Open Chem. Eng. J., vol. 4, pp. 11-20, 2010.

[3] G. Zahedi, S. Azizi, T. Hatami, L. Sheikhattar, "Gray box modeling of supercritical nimbin extraction from neem seeds using methanol as co-solvent", Open Chem. Eng. J., vol. 4, pp. 21-30, 2010.

[4] A. Martín, S. Varona, A. Navarrete, M. J. Cocero, "Encapsulation and co-precipitation processes with supercritical fluids: applications with essential oils", Open Chem Eng J., vol. 4, pp. 31-41, 2010.

[5] D. T. Santos, M. A. A. Meireles, "Carotenoid pigments encapsulation: fundamentals, techniques and recent trends", Open Chem. Eng. J., vol. 4, pp. 42-50, 2010

[6] M. R. Maróstica Junior, A. V. Leite, N. R. V. Dragano, "Supercritical fluid extraction and stabilization of phenolic compounds from natural sources review", Open Chem. Eng. J., vol. 4, pp. 51-60, 2010.

\section{M.A.A. MEIRELES}

Laboratory of Supercritical Technology: Extraction Fractionation, and Identification of vegetable extracts (LASEFI)

Department of Food Engineering (DEA)

University of Campinas (UNICAMP)

Rua Monteiro Lobato, 80, Cid. Universitária Zeferino Vaz 13083-862, Campinas - SP

Brazil

Tel: 00551935214033

E-mail: meireles@ fea.unicamp.br

(C) M.A.A. Meireles; Licensee Bentham Open.

This is an open access article licensed under the terms of the Creative Commons Attribution Non-Commercial License (http://creativecommons.org/licenses/by-nc/3.0/) which permits unrestricted, non-commercial use, distribution and reproduction in any medium, provided the work is properly cited. 